\title{
Influence of Patient Attachment Style on Self-care and Outcomes in Diabetes
}

Paul Ciechanowski, MD, MPH, Joan Russo, PhD, Wayne Katon, MD, Michael Von Korff, ScD, Evette Ludman, PhD, Elizabeth Lin, MD, MPH, Gregory Simon, MD, MPH, and Terry Bush, PhD

\begin{abstract}
Objective: Difficulties collaborating with providers and important others may adversely influence self-management in patients with diabetes. We predicted that dismissing attachment style, characterized by high interpersonal self-reliance and low trust of others, would be associated with poorer self-management in patients with diabetes. Methods: A population-based mail survey was sent to all patients with diabetes from nine primary care clinics of a health maintenance organization. We collected data on attachment style, self-care behaviors, the patient provider relationship and depression status and accessed automated diagnostic, pharmacy, and laboratory data to measure diabetes treatment intensity, medical comorbidity, glycosylated hemoglobin levels, and diabetes complications. We used logistic regression to determine whether dismissing attachment style was associated with poorer diabetes self-care behaviors, adherence to medication, smoking status, and higher glycosylated hemoglobin. Results: In 4095 primary care patients with diabetes, prevalence rates for secure, dismissing, preoccupied, and fearful attachment styles were $44.2 \%, 35.8 \%, 7.9 \%$, and $12.1 \%$, respectively. When compared with secure attachment style, dismissing attachment style was associated with significantly lower levels of exercise $(p=.005)$, foot care $(p<.05)$, diet $(p=.001)$, and adherence to oral hypoglycemic medications $(p<.05)$, and with higher rates of smoking $(p<.05)$, and these associations were mediated through the patient-provider relationship. Preoccupied attachment style, characterized by overreliance on others, was associated with a significantly lower risk of having glycosylated hemoglobin levels $>8 \%$, compared with secure attachment style. Conclusion: Attachment style is significantly associated with diabetes self-management and outcomes. Key words: Attachment theory, diabetes self-care, patientprovider relationship, adherence, dismissing attachment style.
\end{abstract}

$\mathbf{H b}_{\mathbf{A 1}}=$ glycosylated hemoglobin; $\mathbf{G H C}=$ Group Health Cooperative; $\mathbf{B M I}=$ body mass index; $\mathbf{I V}=$ independent variable; $\mathbf{D V}=$ dependent variable.

\section{INTRODUCTION}

A significant proportion of patients with diabetes has poor glycemic control, placing them at higher risk for longterm complications. To minimize health risks, patients with diabetes must regularly attend to diet, foot care, exercise, blood glucose monitoring, appropriate medication adjustment, and quitting smoking. Collaboration and negotiation with health care providers, family members, and others is essential so that such behavior changes are optimally supported and encouraged $(1,2)$.

The positive influence of a collaborative patient-provider relationship may be particularly important and stands as one of the most important determinants of optimal treatment adherence (3). Among diabetic patients specifically, greater satisfaction with one's patient-provider relationship is significantly associated with improved treatment adherence (4) and better metabolic control (5-7).

When health care providers deliver patient-centered care that encompasses compassion, empathy, and responsiveness to patients' needs, values, and expressed preferences (8), patients' participation and autonomy in decision making in-

From the Department of Psychiatry and Behavioral Sciences, University of Washington School of Medicine, Seattle, WA (P.C., J.R., W.K.); and the Center for Health Studies, Group Health Cooperative, Seattle, WA (M.V.K., E. Ludman, E. Lin, G.S., T.B.).

Address correspondence and reprint requests to Paul Ciechanowski, MD, MPH, Department of Psychiatry and Behavioral Sciences, Box 356560, University of Washington School of Medicine, 1959 N. E. Pacific, Seattle, WA 98195-6560. E-mail: pavelcie@u.washington.edu

Received for publication September 25, 2003; revision received April 28, 2004.

Supported by grants \#MH 4-1739 and \#MH 016473 from the National Institute of Mental Health Services Division, Bethesda, MD (Dr. Katon), and by National Institute of Diabetes and Digestive and Kidney Diseases (NIDDK) grant K23 DK60652-01 (Dr. Ciechanowski).

DOI: $10.1097 / 01 . p s y .0000138125 .59122 .23$ creases $(9,10)$, which in turn improves treatment adherence (9,11,12-14). The recent Institute of Medicine report Crossing the Quality Chasm has emphasized the need for patientcenteredness in clinical practice (8). However, the report also reflects diversity in how patients prefer to interact with providers, ranging from patients who seek close relationships with physicians to those who prefer infrequent contact with the physician or with the health care system. The current system of care may better attend to patients with complex health care needs who actively engage in regular clinic appointments compared with patients who make sporadic visits or who prefer less substantial interpersonal relationships (15).

To implement effective patient-centered care, it is important to understand variations in patient interaction styles and patients' capacity to engage with providers. Attachment theory provides a useful conceptual framework and is based on the principle that one's earliest relationships and temperament shape and reinforce perceptions and behaviors in subsequent relationships so that by late adolescence or adulthood, people have a relatively fixed collaborative or attachment style (16). Bowlby proposed that all people psychologically incorporate previous experiences with caregivers, forming enduring cognitive models of caregiving that persist throughout adulthood (16). Such models are learned ways of interacting in relationships throughout life, particularly at times of vulnerability. These models influence whether people deem themselves worthy of care and whether others are perceived as trustworthy to provide care.

Social psychologists have identified four specific patterns of interpersonal attachment behaviors in adults (17): secure, and three insecure styles known as dismissing, preoccupied, and fearful. People may be characterized interpersonally by profiles of varying degrees of each style. However, attachment prototypes may add predictive power over dimensions alone (18), and clinically, it is often more useful to conceptualize people in terms of their predominant attachment style to 
understand better the developmental and behavioral characteristics of each style.

Adults with predominantly secure attachment style are believed to have experienced consistently responsive (19) early caregiving and are generally comfortable depending on and being readily comforted by others. Adults with predominantly dismissing attachment style are posited to have experienced early caregiving that was consistently emotionally unresponsive, and from an early age, they develop strategies in which they become highly self-reliant (20) and uncomfortable trusting others. On the other hand, adults with predominantly preoccupied attachment style experienced inconsistently responsive caregiving (21); to ensure proximity to caregivers, they learned to do more than their share in attachment relationships. They are generally emotionally dependent on others' approval and generally have poor self-esteem. People with a predominantly fearful attachment style also may desire social contact, but this desire is inhibited by fear of rejection. They are hypothesized to have had overly critical or harshly rejecting caregiving, and as adults are more likely to demonstrate approach-avoidance behavior interpersonally, stemming from a fear of intimacy (22). A large epidemiological survey of the US general population reports that $55 \%$ of the population has a secure attachment style, with the three insecure attachment styles making up the remainder (23).

Researchers hypothesize that patients who are more selfreliant and less trusting of others may have poorer collaboration with health care providers, which may adversely affect diabetes self-care. Three small to medium-sized studies of patients with diabetes have shown that dismissing attachment style is associated with higher glycohemoglobin levels (24), poorer adherence with glucose testing and insulin injections (25), and in the setting of a poor patient-provider relationship with higher glycohemoglobin, poorer glucose testing and poorer adherence to oral hypoglycemic medications (26). In the current study, we examine the association of attachment style with treatment adherence and outcomes in a large, representative sample of primary care patients with diabetes.

In this article, we addressed the following questions:

1. What is the prevalence of attachment styles in a large, representative population of primary care patients with diabetes?

2. Compared with patients with secure attachment style, do patients with dismissing attachment style have poorer adherence to diet, exercise, glucose testing, foot care, and oral hypoglycemic medications, and are they more likely to smoke cigarettes and have higher glycosylated hemoglobin $\left(\mathrm{Hb}_{\mathrm{A} 1 \mathrm{c}}\right)$ levels?

3. If attachment style is associated with poorer adherence to diabetes self-care, increased risk of smoking, or higher $\mathrm{Hb}_{\mathrm{Alc}}$ levels, is this relationship mediated through the patient-provider relationship?

\section{METHODS}

The Pathways Study was developed by a multidisciplinary team in the Department of Psychiatry at the University of Washington and the Center for
Health Studies at Group Health Cooperative (GHC) (27) and set out to determine behavioral and clinical characteristics of diabetes associated with depression in a representative primary care population. Assessment of attachment style and patient-provider relationships was an integral part of the analysis plan. GHC is a nonprofit health maintenance organization with 30 primary care clinics in western Washington state. The study protocol was approved by institutional review boards at the University of Washington and GHC.

\section{Study Setting}

Nine GHC primary care clinics were selected for the study based on three criteria: a) clinics with the largest number of diabetic patients, b) clinics within a 40-mile geographic radius of Seattle, and c) clinics with the most racial and ethnic diversity.

\section{Sample Recruitment}

Case identification was facilitated by GHC's previous development of a population-based diabetes registry (28). Patients are added to the registry based on a) currently taking any diabetic agent; b) a fasting glucose $\geq 126$ $\mathrm{mg} / \mathrm{dl}$, confirmed by a second out-of-range test within 1 year; c) a random plasma glucose $\geq 200 \mathrm{mg} / \mathrm{dl}$, confirmed by a second test within 1 year; or d) a hospital discharge diagnosis of diabetes at any time during GHC enrollment or two outpatient diagnoses of diabetes (28).

Patients were surveyed by mail in sequential waves with approximately 700 questionnaires sent per month. A $\$ 3$ gift certificate for a local store was included with the mailing to encourage response. A second mailing, followed by a telephone reminder call for nonrespondents, was associated with a $62 \%$ final response rate.

\section{Self-report Measures Attachment Style}

Participants completed the Relationship Questionnaire (18), which is an instrument measuring attachment style of respondents. Four paragraphs are presented describing secure, preoccupied, fearful, and dismissing attachment styles, and subjects are asked to choose the style that best suits them. The items have shown convergent and discriminant validity with other self-report measures and interview ratings (18). Scharfe and Bartholomew (30) found moderate stability of the Relationship Questionnaire over a period of approximately 2 months, ranging from a low of 0.49 to a high of 0.71 . Sample sentences from the four paragraphs include the following: secure: "It is easy for me to become emotionally close to others," "I am comfortable depending on them and having them depend on me"; dismissing: "It is very important to me to feel independent and self-sufficient," "I prefer not to depend on others or have others depend on me"; fearful: "I am uncomfortable getting close to others," "I worry that I will be hurt if I allow myself to become too close to others"; and preoccupied: "I want to be completely emotionally intimate with others," "I am uncomfortable being without close relationships."

\section{Diabetes Self-care}

We used a brief valid self-report questionnaire, the Summary of Diabetes Self-Care Activities, to assess four diabetes self-care domains: diet, exercise, blood glucose testing, and foot care (31). Each domain consists of two items, which are averaged and assess adherence to self-care over the period of the previous week. For diet, we used the general diet score. We dichotomized the results of the questionnaire to create an indicator variable for being in the lowest 25 th percentile of adherence in each domain. We also determined categorically patients' smoking status based on an item from the Summary of Diabetes Self-Care Activities.

\section{Depression Status}

The Patient Health Questionnaire (PHQ-9) provided dichotomous diagnoses of minor and major depression. The Patient Health Questionnaire major depression diagnosis has been found to have high agreement with that based on structured interviews (32). The criteria for major depression required the patient to have, for at least 2 weeks, five or more depressive symptoms present 
for more than half of the days, with at least one of these symptoms either depressed mood or anhedonia $(32,33)$. The criteria for minor depression required the patient to have, for at least 2 weeks, two to four depressive symptoms present for more than half of the days, with at least one of these symptoms either depressed mood or anhedonia $(32,33)$.

\section{Patient-Provider Relationship}

To assess the patient-provider relationship, we used 3 items from a 10 -item scale developed for assessing the patient-provider relationship in bipolar illness (34). These items are similar in content to other scales measuring self-management support, including the Assessment of Chronic Illness Care (35). We revised the questions for suitability to a diabetic population: "My doctor who treats my diabetes regularly reviews with me how I am doing in managing all aspects of my diabetes;" "My doctor who treats my diabetes makes regular calls to find out how I'm doing managing my diabetes;" "My doctor who treats my diabetes has worked with me to develop a plan so that I know how to take care of my diabetes." Participants rated items from 1 (strongly disagree) to 7 (strongly agree). In the present study, the internal consistency $(\alpha)$ coefficient was 0.80 .

\section{Demographic and Clinical Characteristics}

Data were collected on age, sex, years of education, ethnicity, marital status, and clinical status, including height and weight, from which body mass index (BMI, $\mathrm{kg} / \mathrm{m}^{2}$ ) was assessed. Patients were diagnosed as having type 1 diabetes if age of onset was $<30$ years, insulin was the first treatment prescribed, and they were currently on insulin.

\section{Automated Data \\ Medical Comorbidity}

Computerized pharmacy records were used to compute a measure of medical comorbidity (Rx Risk) based on prescription drug use over the period of the previous 12 months (36). The Rx Risk is comparable with using Ambulatory Care Groups (37) in predicting total future health costs (36).

\section{Treatment Intensity}

Pharmacy data regarding oral hypoglycemic agent and insulin use indicated the intensity of treatment.

\section{Oral Hypoglycemic Adherence}

Adherence to oral hypoglycemic agents was assessed in the $60.2 \%$ of patients who had one or more prescription fills of this class of medication in the 1-year observation period before questionnaire administration. Based on automated pharmacy refill data, total possible days of exposure (denominator) to oral hypoglycemic agents was either 365 days or number of days from the patient's first fill date in the previous year. For patients for whom the first fill occurred in the previous year, we checked data going back another 6 months to ensure that the first fill was not actually a refill after a recent gap in use. The number of actual days of oral hypoglycemic agent use (numerator) was the sum of total days supplied within this window of observation multiplied by 1.25 to allow a $25 \%$ grace period (38). Adherence was determined by (total days supplied $\times 1.25) \div$ (total possible days of exposure), and a categorical score of adherence was derived by dichotomizing the sample into those who were and were not $100 \%$ adherent.

\section{Diabetes Complications}

We used automated diagnostic International Classification of Diseases- 9 code data for seven types of diabetic complications (retinopathy, nephropathy, neuropathy, cerebrovascular, cardiovascular, peripheral vascular, and metabolic).

\section{Glycohemoglobin}

Group Health Cooperative automated data on $\mathrm{Hb}_{\mathrm{Alc}}$ levels for the 12 months before screening were used for this study. Because our main independent variable, attachment style, was a trait characteristic, we used the most recent $\mathrm{Hb}_{\mathrm{Alc}}$ level within the 12 months before the questionnaire. $\mathrm{Hb}_{\mathrm{Alc}}$ is accepted as the best measure of recent glycemic control (within the last 120 days) and is used to guide clinical management (39).

\section{Statistical Analysis}

We examined differences between survey respondents' and nonrespondents' automated data using $t$-tests for continuous data and $\chi^{2}$ tests with corrections for continuity for categorical data. Because of the concern of nonresponse bias, we developed a propensity score to estimate response probability to determine whether survey results should be weighted for nonresponse. Automated data from survey respondents and nonrespondents were used to estimate response propensity scores (the probability of being a respondent) as a function of the following (all within the last year): age; sex; most recent $\mathrm{Hb}_{\mathrm{Al} 1 \mathrm{c}}$ value; treated with insulin; used oral hypoglycemic medications; received specialty mental health care; received a depression diagnosis; filled any prescriptions for an antidepressant medication; hospitalization; Rx Risk, score omitting medications for diabetes and mental disorders; number of primary care visits; number of specialty care visits; membership on the GHC heart disease registry; and primary care clinic location. We compared weighted and unweighted analyses to determine whether postsurvey adjustment for factors related to nonresponse resulted in meaningful differences in survey estimates and observed only trivial differences in estimates, so we report analyses based on observed data in this article.

\section{Baseline Characteristics}

To examine group differences between attachment styles on demographic and clinical variables, $\chi^{2}$ tests were used for categorical variables, and analyses of variance were used for continuous measures. We conducted post hoc tests to determine between which groups any significant differences appeared.

\section{Main Outcome Analyses}

We used logistic regression to determine whether attachment style was an independent predictor of poor diabetes self-care. Our dependent variables were indicator variables addressing the following: the lowest 25 th percentile for adherence in the domains of diet, exercise, glucose testing, and foot care; $<100 \%$ adherence with oral hypoglycemic agents (among those taking these medications); positive smoking status; and having a $\mathrm{Hb}_{\mathrm{Alc}}$ level $>8 \%$. Our independent variable was patient attachment style, with the secure group as the reference group. The covariates in these models were age, sex, race, marital status, education level, number of diabetes complications, an indicator variable for major and minor depression, obesity (BMI $\geq 30 \mathrm{~kg} / \mathrm{m}^{2}$ ), clinic, Rx Risk score, and treatment intensity. For analysis of oral hypoglycemic medication adherence, we substituted treatment intensity with a dichotomous variable indicating whether patients were on insulin.

\section{Mediation Analyses}

To determine whether the patient-provider relationship mediates the relationship between attachment style and diabetes adherence or health outcomes, we tested four conditions that must hold to show mediation (40):

1. The independent variable (IV; attachment style) must significantly affect the dependent variable (DV; adherence or health outcome) when regressing the DV on the IV

2. The IV (attachment style) must significantly affect the mediator (patient-provider relationship) when the mediator is regressed on the IV

3. The mediator (patient-provider relationship) must significantly affect the DV (adherence or health outcome) when regressing the DV on both the IV and on the mediator

4. The effect of the IV on the DV must be less when the mediator is controlled as in 3 than when it is not, as in 1

For condition 1, we used the logistic regression results from the main outcome analyses here and proceeded with those domains of treatment adherence or health outcomes whose models were statistically significant. To examine condition 2, we used analysis of covariance with 3 one degree of freedom contrasts (comparing secure with fearful, preoccupied, and dismissing attachment style) with similar covariates as in the main analyses to determine whether the attachment style groups were related to the patient- 


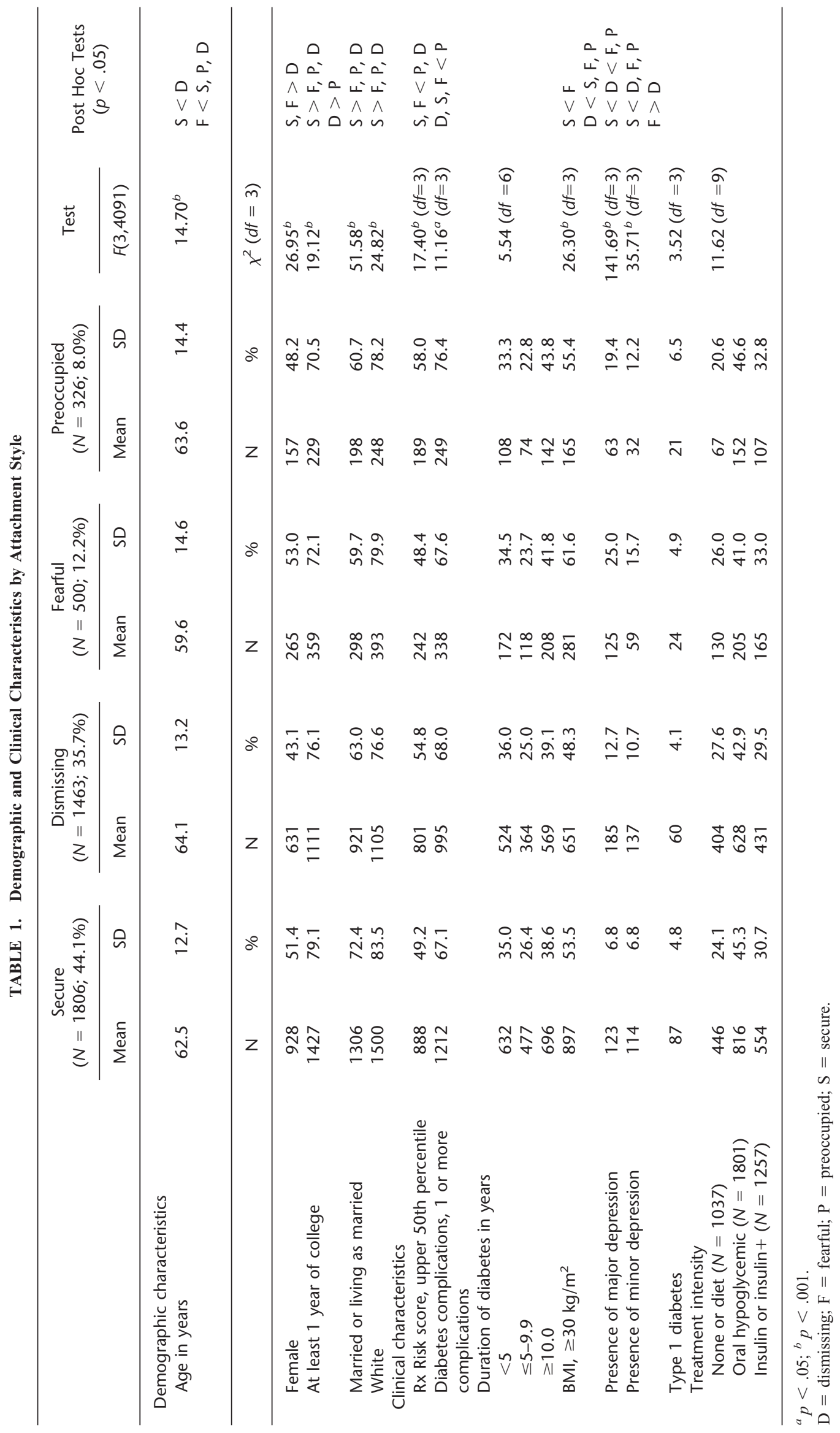


provider relationship. To test condition 3, we fit a logistic regression model with both attachment style and the patient-provider relationship. In this model, we examined the significance of the mediator and the change in the Wald $t$ to determine whether mediation was demonstrated (condition 4). For the instances in which mediation was demonstrated (when all four conditions were met), we calculated the proportion of the relationship between attachment style and adherence or health outcome that was mediated by the patient-provider relationship, using the methods of Shrout and Bolger (41). This method allows us to represent the strength of the mediation on a continuum of 0 to 1 rather than categorically as whether mediation occurred or not.

\section{RESULTS}

Of 4839 subjects who returned questionnaires $(61.7 \%$ of eligible patients), 372 did not give permission for access to medical records, and 458 did not complete the attachment measure, leaving a sample of 4095 patients. Attachment style prevalence rates for secure, dismissing, preoccupied, and fearful attachment style among these patients were $44.1 \%, 35.7 \%$, $8.0 \%$, and $12.2 \%$, respectively. Of the 372 patients who did not permit access to automated data, 288 had completed attachment style questions, among whom $37.2 \%, 42.4 \%$, $7.6 \%$, and $12.8 \%$ had a secure, dismissing, preoccupied, and fearful attachment style, respectively; although proportionately more patients with dismissing attachment style and fewer patients with secure attachment style were represented among these patients, differences were not statistically significant. Patients were ethnically diverse, with $79.6 \%$ of the sample white, 9.4\% Asian or Pacific Islander, 8.3\% African American, and 1.5\% American Indian or Alaskan Native.

Table 1 presents the demographic characteristics stratified by attachment style. Patients with dismissing attachment style were significantly less likely than patients with secure or fearful attachment style to be female. Patients with secure attachment style were more likely to be married, to be white, and to have postsecondary education compared with patients with fearful, preoccupied, and dismissing attachment styles. Patients with dismissing attachment style were more likely to have postsecondary education compared with patients with preoccupied attachment style. Patients with fearful attachment style were younger than patients with secure, preoccupied, and dismissing attachment styles, and patients with secure attachment style were younger than those with dismissing attachment style.

Table 1 also presents the clinical characteristics stratified by attachment style. Patients with preoccupied and dismissing attachment style had significantly greater nondiabetic medical comorbidity compared with patients with secure and fearful attachment style, and patients with preoccupied attachment style were more likely to have one or more diabetes complications compared with patients with the other attachment styles. Patients with preoccupied attachment style were more likely to be obese (BMI $>=30 \mathrm{~kg} / \mathrm{m}^{2}$ ) compared with patients with dismissing and secure attachment styles, and patients with dismissing attachment style were less likely to be obese compared with patients with fearful and secure attachment styles. Patients with secure attachment style were the least likely to have major depression styles, and those with fearful and preoccupied attachment have major depression styles were the most likely to have major depression.

Table 2 provides the results of analyses assessing the odds of nonadherence to diabetes self-care between attachment styles after adjustment for covariates. Patients with dismissing attachment style were significantly more likely to have lower levels of exercise, foot care, and healthful diet, but not glucose testing compared with patients with secure attachment style. Patients with dismissing attachment were also more likely to smoke and more likely to be nonadherent with oral hypoglycemic medications compared with patients with secure attachment style. Patients with fearful attachment style were less likely than patients with secure attachment style to exercise. Patients with preoccupied attachment style were significantly less likely to have $\mathrm{Hb}_{\mathrm{Alc}}$ levels $>8 \%$ compared with those with secure attachment style.

TABLE 2. Self-care Behaviors and Diabetes Outcomes by Attachment Style

\begin{tabular}{|c|c|c|c|c|c|c|c|}
\hline \multirow{2}{*}{\multicolumn{2}{|c|}{ Adherence Domain }} & \multicolumn{2}{|c|}{$\begin{array}{c}\text { Dismissing } \\
(N=1463 ; 35.7 \%)\end{array}$} & \multicolumn{2}{|c|}{$\begin{array}{c}\text { Fearful } \\
(N=500 ; 12.2 \%)\end{array}$} & \multicolumn{2}{|c|}{$\begin{array}{c}\text { Preoccupied } \\
(N=326 ; 8.0 \%)\end{array}$} \\
\hline & & Odds Ratio ${ }^{a}$ & $95 \% \mathrm{Cl}$ & Odds Ratio ${ }^{a}$ & $95 \% \mathrm{Cl}$ & Odds Ratio ${ }^{a}$ & $95 \% \mathrm{Cl}$ \\
\hline General diet (lowest 25th percentile) & & 1.41 & $1.17,1.69$ & 1.16 & $.89,1.51$ & 1.15 & $.84,1.58$ \\
\hline Exercise (lowest 25th percentile) & & 1.36 & $1.13,1.62$ & 1.33 & $1.03,1.71$ & .92 & $.67,1.27$ \\
\hline Glucose testing (lowest 25 th percentile) & & 1.15 & $.95,1.38$ & 1.14 & $.87,1.50$ & 1.21 & $.88,1.67$ \\
\hline Foot care (lowest 25th percentile) & & 1.21 & $1.02,1.45$ & 1.19 & $.93,1.54$ & 1.04 & $.76,1.42$ \\
\hline Current smoker (lowest 25th percentile) & & 1.42 & $1.08,1.86$ & 1.28 & $.88,1.86$ & 1.00 & $.61,1.63$ \\
\hline \multirow[t]{2}{*}{$\mathrm{Hb}_{\mathrm{A} 1 \mathrm{c}}$ level $>8 \%$ (lowest 25 th percentile) } & & 1.05 & $.88,1.24$ & .95 & $.74,1.20$ & .66 & $.49, .90$ \\
\hline & \multicolumn{3}{|c|}{$\begin{array}{c}\text { Dismissing }^{b} \\
(N=849 ; 34.9 \%)\end{array}$} & \multicolumn{2}{|c|}{$\begin{array}{c}\text { Fearful }^{b} \\
(N=297 ; 12.2 \%)\end{array}$} & \multicolumn{2}{|c|}{$\begin{array}{c}\text { Preoccupied }^{b} \\
(N=205 ; 8.4 \%)\end{array}$} \\
\hline Oral hypoglycemic adherence & 1.23 & \multicolumn{2}{|c|}{$1.01,1.51$} & \multicolumn{2}{|r|}{$.98,1.77$} & 1.33 & $.93,1.89$ \\
\hline
\end{tabular}

${ }^{a}$ Odds ratios of nonadherence in each adherence domain for each attachment style as compared to reference group, secure attachment style. Models adjusted for age, gender, race, education level, marital status, depression, diabetes complications, BMI, medical illness comorbidity, treatment intensity and clinic.

${ }^{b}$ Sample size determined by patients on oral hypoglycemic agents. 
In our mediation analyses, we found that attachment style was significantly associated with the patient-provider relation$\operatorname{ship}(F[3,3572]=11.6 ; p<.0001)$. Planned contrasts revealed higher mean total patient-provider scores, indicating greater patient-provider collaboration among patients with secure attachment style $(4.99 ; \mathrm{SD}=1.53)$ compared with patients with fearful $(4.62$; $\mathrm{SD}=1.51 ; p<.001)$ and dismissing $(4.71 ; \mathrm{SD}=1.50 ; p<.001)$ but not preoccupied (4.89; $\mathrm{SD}=1.50 ; p=.30)$ attachment styles.

Table 3 summarizes the remaining results of mediation analysis. Greater patient-provider collaboration was significantly associated with better adherence to diet, exercise, foot care, and oral hypoglycemic medications and with lower likelihood of $\mathrm{Hb}_{\mathrm{Alc}}$ value $>8 \%$ or of positive smoking status when attachment style was also in the model. The relationship between dismissing attachment style and poorer adherence to diet, exercise, foot care, oral hypoglycemic medications, or positive smoking status was mediated through the patientprovider relationship, with the proportion mediated ranging from 0.22 for foot care to 0.07 for smoking. There was also mediation of the relationship of fearful attachment style and poor adherence to exercise through the patient-provider relationship, with the proportion mediated 0.14 . Finally, there was mediation of the relationship between preoccupied attachment style and lower likelihood of having a $\mathrm{Hb}_{\mathrm{A} 1 \mathrm{c}}$ value $>8 \%$ through the patient-provider relationship; however, the proportion mediated was very small $(0.01)$.

\section{DISCUSSION}

One third of this primary care diabetic patient sample reported having dismissing attachment style. Patients with a dismissing attachment style were less adherent with diet, exercise, foot care, and oral hypoglycemic medications, were more likely to smoke, and viewed the patient-provider relationship less favorably as compared with patients with a secure attachment style. Mediation analyses suggested the relationship between dismissing attachment style and adherence with self-care was mediated through the patient-provider relationship.

These findings are consistent with characteristics of dismissing attachment style. People with such a style may be more likely to find social interactions unrewarding (42) and to view others as consistently unavailable or incapable of providing care and thus may tend to avoid relying on others $(20,42)$. Their presentation to health care providers may be construed as if they are invulnerable and not in need of their provider's care or expertise (43). They may not elaborate on their problems, symptoms, illness (44), or the effect of their illness because of reluctance to elicit support from others. Although our self-report findings regarding the patient-provider relationship could be interpreted as indicating that patients with dismissing attachment style perceived their providers as less available, it is also possible that such patient characteristics resulted in less involvement by the provider

TABLE 3. Mediation Analyses ${ }^{a}$

\begin{tabular}{|c|c|c|c|c|c|c|c|c|c|}
\hline \multirow[t]{2}{*}{ Adherence domain } & \multicolumn{2}{|c|}{$\begin{array}{l}\text { Patient-provider } \\
\text { relationship }\end{array}$} & \multicolumn{2}{|c|}{$\begin{array}{c}\text { Dismissing } \\
(N=1463 \\
35.7 \%)\end{array}$} & \multicolumn{2}{|c|}{$\begin{array}{c}\text { Fearful } \\
(N=500 ; 12.2 \%)\end{array}$} & \multicolumn{2}{|c|}{$\begin{array}{c}\text { Preoccupied } \\
(N=326 ; 8.0 \%)\end{array}$} & \multirow{2}{*}{$\begin{array}{l}\text { Effect proportion } \\
\text { mediated }^{b}\end{array}$} \\
\hline & Wald $t$ & $p$ & Wald $t$ & $p$ & Wald $t$ & $p$ & Wald $t$ & $p$ & \\
\hline \multirow[t]{2}{*}{ General diet } & 49.4 & $<.001$ & 12.9 & $<.001$ & 1.2 & .28 & .77 & .38 & .16 for dismissing \\
\hline & & & 9.4 & .002 & .21 & .65 & .47 & .49 & \\
\hline \multirow[t]{2}{*}{ Exercise } & 14.7 & $<.001$ & 10.9 & .001 & 4.8 & .03 & .25 & .62 & .09 for dismissing \\
\hline & & & 8.2 & .004 & 2.9 & .09 & .17 & .68 & .14 for fearful \\
\hline \multirow[t]{2}{*}{ Foot care } & 33.7 & $<.001$ & 4.5 & .03 & 1.9 & .17 & .06 & .82 & .22 for dismissing \\
\hline & & & 3.5 & .06 & 1.4 & .24 & .02 & .88 & \\
\hline \multirow[t]{2}{*}{ Current smoker } & 4.9 & .03 & 6.2 & .01 & 1.7 & .19 & .00 & .99 & .07 for dismissing \\
\hline & & & 5.7 & .02 & .86 & .36 & .00 & .96 & \\
\hline \multirow[t]{4}{*}{$\mathrm{Hb}_{\mathrm{A} 1 \mathrm{c}}$ level $>8 \%$} & 4.3 & .04 & .29 & .59 & .18 & .67 & 7.1 & .008 & .01 for preoccupied \\
\hline & & & .39 & .54 & .04 & .84 & 6.7 & .010 & \\
\hline & \multicolumn{2}{|c|}{$\begin{array}{l}\text { Patient-provider } \\
\text { relationship }\end{array}$} & \multicolumn{2}{|c|}{$\begin{array}{c}\text { Dismissing }{ }^{c} \\
(N=849 ; 34.9 \%)\end{array}$} & \multicolumn{2}{|c|}{$\begin{array}{c}\text { Fearful }^{c} \\
(N=297 ; 12.2 \%)\end{array}$} & \multicolumn{2}{|c|}{$\begin{array}{c}\text { Preoccupied }^{c} \\
(N=205 ; 8.4 \%)\end{array}$} & \\
\hline & Wald $t$ & $p$ & Wald $t$ & $p$ & Wald $t$ & $p$ & Wald $t$ & $p$ & \\
\hline \multirow[t]{2}{*}{ Oral hypoglycemic adherence } & 3.8 & .049 & 4.1 & .04 & 3.2 & .07 & 2.4 & .12 & .08 for dismissing \\
\hline & & & 2.7 & .10 & 2.3 & .13 & 2.4 & .12 & \\
\hline
\end{tabular}

\footnotetext{
${ }^{a}$ Based on logistic regression with independent variable attachment style (secure attachment style is reference group). Results shown in first line of each cell represents models adjusted for age, gender, race, education level, marital status, depression, diabetes complications, BMI, medical illness comorbidity, treatment intensity and clinic. Results in the second line include the addition of the patient-provider relationship as a covariate.

${ }^{b}$ Proportion of relationship between attachment style and adherence mediated through patient-provider relationship. Proportion calculated when mediation demonstrated according to four conditions of Baron and Kenny (1986).

${ }^{c}$ Sample size determined by patients on oral hypoglycemic agents.
} 
caring for the patient's diabetes. Future observational studies with objective measurement of the patient-provider relationship are needed to explore this possibility.

One of the key features of dismissing attachment style, self-sufficiency, which is highly valued in Western societies, seems to be a positive attribute that should be associated with greater initiative and motivation toward self-care. However, in certain contexts, high interpersonal self-sufficiency can be as much of a disadvantage as an asset. In the management literature, being highly independent is considered a less effective way of succeeding in organizations, marriage and family, compared with being interdependent (45). Counterdependence is a characteristic related to dismissing attachment style that describes people in management or medical settings who overinvest in work activities, resist supportive overtures, and tend to self-isolate $(46,47)$. In health care, as one shifts from a state of health to mild chronic disease to more severe disease, interpersonal self-sufficiency may increasingly become an obstacle to collaboration with family and the medical system for successful disease self-management. In a complex illness such as diabetes, high self-sufficiency may interfere with critical interpersonal interactions that would facilitate disease self-management such as negotiation with spouse and family regarding dietary changes, arranging to take time off from work or family for exercise and medical appointments, and learning from and collaborating with one's health care provider and team.

Diabetes self-care behaviors can be thought of as existing on a continuum from being less to more relationship-dependent. Diet and exercise are self-care behaviors that often involve and depend on important others (e.g., guidance from a health care provider, meal preparation in a family context, exercising with a partner or group). Glucose monitoring, a relatively quick and straightforward procedure, is relatively less relationship-dependent. We found that patients with diabetes and dismissing attachment style were significantly less likely to follow diet and exercise regimens, whereas attachment style was not associated with glucose monitoring frequency. In a previous study in which dismissing attachment was associated with poor glucose monitoring, the finding was a result of an interaction of predominantly patients with type 2 diabetes in whom patient-provider communication was rated as poor (26). Another study in which an association between dismissing attachment and poor glucose monitoring was found involved patients with type 1 diabetes (25), who by necessity take insulin and monitor glucose significantly more frequently than patients with type 2 diabetes.

Foot care, which requires inspecting feet thoroughly to check for abrasions, lesions, and early infections, may be thought of as a relatively solitary activity. However, we found that adherence to foot care was significantly poorer among patients with dismissing attachment style. The prospect of having to depend on a health care provider should a lesion be identified may make it less desirable for patients with a dismissing attachment style to search for foot lesions.

We also found that dismissing attachment style was asso- ciated with higher rates of smoking. Patients with dismissing attachment style may have fewer opportunities to interact with healthcare providers, as suggested by our mediation analyses, and to receive the recurring advice and support for quitting smoking that has been shown to be related to successful cessation. Also, smoking, like overeating and drinking, may be thought of as a way of coping with upsetting emotions without depending on other people (48).

Congruent with theory, preoccupied attachment style, which is associated with dependence on others, was associated with lower $\mathrm{Hb}_{\mathrm{Alc}}$ values compared with secure attachment style. In a previous study we showed that primary care patients with preoccupied attachment style had significantly more health visits and reported significantly more physical symptoms than patients with secure attachment style (49). Patients with diabetes who have preoccupied attachment style may also attend clinics more often, report more symptoms, and receive more testing and care related to their diabetes. Because of their support-seeking attachment style, these patients may be more likely to try to please significant others and health care professionals $(49,50)$.

Glycosylated hemoglobin levels were not significantly greater among patients with dismissing attachment style in this large sample. A previous study of patients with type 1 diabetes found a strong association between dismissing attachment style and higher $\mathrm{Hb}_{\mathrm{Alc}}$ levels (24). This discrepancy in findings between studies may have to do with the fact that the complete insulin deficiency in type 1 diabetes may result in greater lability in glycemic control in response to behavioral perturbations than may be the case in type 2 diabetes (51).

Overall, in our population, prevalence of dismissing attachment style $(35.8 \%)$ was higher and that of secure attachment style $(44.2 \%)$ lower than in the general population $(25 \%$ and $55 \%$, respectively). A recent study (52) has suggested that clinical factors associated with depression (e.g., less adherence with dietary, weight loss, and physical activity recommendations) resulted in a significantly increased risk of developing type 2 diabetes in depressed versus non-depressed patients. Similarly, patients with dismissing attachment style may also be at greater risk of developing type 2 diabetes as a result of poorer lifelong habits that precede onset of diabetes. However, longitudinal studies that follow nondiabetic people over time are needed to confirm this. It is also possible that in this older age population, patients endorse items that are associated with more self-reliance, reflecting recent adaptations they may have made in their lives as opposed to lifelong traits.

There are several strengths and limitations in this study. This is a large, representative primary care population sample of patients with diabetes for which we had access to automated data to determine treatment intensity, $\mathrm{Hb}_{\mathrm{Alc}}$ values, and indices of comorbidity and complications. However, this was a cross-sectional study, and we are limited in the ability to make causal inferences. Because attachment style is a relatively stable trait (53-56), however, it likely predicts the outcomes of these analyses, and not the other way around. 
Also, it is possible that data on attachment style gathered through semistructured interviews (57) might have been less subject to social desirability biases (we did not measure social desirability directly), but such methods would not allow attachment style data to be accrued on such a large sample size. Although we had automated data to assess some of the adherence data, we also depended on self-report data, which is subject to social desirability and recall biases. Although our use of pharmacy data to assess oral hypoglycemic adherence reduced such biases, pharmacy data based on refill purchases may not be as accurate an indicator of medications the patient actually took compared with methods using electronic pill monitors or serum levels of medications.

\section{Future Directions}

Based on the results of this study, it may be useful, in clinical and research settings, to identify the attachment style of patients with diabetes. There are a number of brief attachment self-report instruments like the Relationship Questionnaire $(17,58)$ that can be used in a clinical or research setting. Although a third of patients in our population-based sample had dismissing attachment style, this proportion may be even greater among patients who have difficulty with self-care. Patients with dismissing attachment style in this sample were more likely to smoke and had lower adherence to diet, exercise, and foot care, putting them at greater risk for macrovascular complications, even if their $\mathrm{Hb}_{\mathrm{Alc}}$ levels were not significantly elevated compared with patients with secure attachment style.

Future randomized controlled intervention trials are necessary to determine whether interventions based on attachment theory are effective in improving patient collaboration and treatment adherence. Interventions may potentially be organized at the patient, provider, patient-provider, clinic, and population-based levels. For example, improved treatment adherence might be facilitated by strategies that respect the autonomy and need for increased interpersonal distance and by strategies that enhance perceived personal control among patients with dismissing attachment style (59). Increasing patient empowerment (2) or techniques based on motivational interviewing (60) or relationship-focused problem-solving therapy (61) may be useful to help the patient with dismissing attachment style to work collaboratively with providers without feeling that their need for self-reliance is threatened.

Understanding the attachment style of patients who have difficulties with self-care may also facilitate use of other health services interventions. Incorporating use of automated tracking of appointments; increased communication through telephone calls and e-mail and other Web-based communication; and use of proactive contacts such as mailed reminders of appointments may augment care of patients with dismissing attachment style (62). Stepped care approaches in which patients with dismissing attachment style with poor adherence to self-care are referred to nurse case managers, social workers, or other clinicians with expertise in psychological medicine may be fruitful by providing a plan to optimize patientprovider contact.

Attachment theory helps to explain in developmental terms what experienced providers come to know through repeated patient-provider interactions, ie, different patients require different provider approaches. By using this theoretical framework to develop effective interventions, we may be able to respond better to the unique interpersonal characteristics of our patients and, in the process, recognize our own interpersonal styles that are an essential part of the patient-provider interaction.

\section{REFERENCES}

1. Day JL, Bodmer CW, Dunn OM. Development of a questionnaire identifying factors responsible for successful self-management of insulintreated diabetes. Diabet Med 1996;13:564-73.

2. Anderson RM. Patient empowerment and the traditional medical model: a case of irreconcilable differences? Diabetes Care 1995;18:412-5.

3. McLane CG, Zyzanski SJ, Flocke SA. Factors associated with medication noncompliance in rural elderly hypertensive patients. Am J Hypertens 1995;8:206-9.

4. Sherbourne CD, Hays RD, Ordway L, DiMatteo MR, Kravitz RL. Antecedents of adherence to medical recommendations: results from the Medical Outcomes Study. J Behav Med 1992;15:447-68.

5. Kaplan SH, Greenfield S, Ware JE. Assessing the effects of physicianpatient interactions on the outcomes of chronic disease. Med Care 1989; 27(suppl 3):S110-27.

6. Greenfield S, Kaplan SH, Ware JE, Yano EM, Frank HJ. Patients' participation in medical care-effects on blood sugar control and quality of life in diabetes. J Gen Intern Med 1988;3:448-57.

7. Viinamaki H, Niskanen L, Korhonen T, et al. The patient-doctor relationship and metabolic control in patients with type 1 (insulin-dependent) diabetes mellitus. Intern J Psychiatry Med 1993;23:265:1097-102.

8. Committee on Quality of Health Care in America. Crossing the quality chasm: a new health system for the 21 st century. Washington, DC: National Academy Press; 2001.

9. Stewart MA. Effective physician-patient communication and health outcomes: a review. CMAJ 1995;152:1423-33.

10. Ende J, Kazis L, Ash A, Moskowitz MA. Measuring patients' desire for autonomy: decision making and information-seeking preferences among medical patients. J Gen Intern Med 1989;4:23-30.

11. Hall JA, Roter DL, Datz NR. Meta-analysis of correlates of provider behavior in medical encounters. Med Care 1988;26:657.

12. Von Korff M, Gruman J, Schaefer J, Curry SJ, Wagner EH. Collaborative management of chronic illness. Ann Intern Med 1997;19:1097-102.

13. Roter D, Hall JA. Doctors talking with patients/ patients talking with doctors: improving communication in medical visits. Westport, CT: Auburn House; 1992. p. 203.

14. Noble LM. Doctor-patient communication and adherence to medication. In: Myers LB, Midence K, editors. Adherence to treatment in medical conditions. Amsterdam: Harwood Academic Publishers; 1998. p. 51-73.

15. Karter AJ, Parker MM, Moffet HH, Ahmed AT, Ferrara A, Liu JY, Selby JV. Missed appointments and poor glycemic control: an opportunity to identify high-risk diabetic patients. Med Care 2004;42:110-5.

16. Bowlby J. Attachment and loss, vol. II: separation: anxiety and anger. New York: Basic Books; 1973.

17. Bartholomew K, Horowitz LM. Attachment styles among young adults: a test of a four-category model. J Pers Soc Psychol 1991;61:226-44.

18. Griffin DW, Bartholomew K. The metaphysics of measurement: the case of adult attachment. Adv Pers Relat 1994;5:17-52.

19. Ainsworth MS, Blehar MC, Waters E, Wall S. Patterns of attachment: a psychological study of the strange situation. Hillsdale, NJ: Erlbaum; 1978.

20. Bowlby J. The making and breaking of affectional bonds. Br J Psychiatry 1977;130:201-10.

21. Bartholomew K. Avoidance of intimacy: an attachment perspective. J Soc Pers Relat 1990;7:147-78.

22. Bartholomew K. From childhood to adult relationships: attachment theory and research. In: Duck S, editor. Learning about relationships: un- 
derstanding relationships processes series, vol. 2. Newbury Park: Sage Publications; 1993.

23. Mickelson KD, Kessler RC, Shaver PR. Adult attachment in a nationally representative sample. J Pers Soc Psychol 1997;73:1092-106.

24. Ciechanowski PS, Hirsch IB, Katon WJ. Interpersonal predictors of HbAlc in patients with type 1 diabetes. Diabetes Care 2002;25:731-6.

25. Turan B, Osar Z, Turan JM, Ilkova H, Damci T. Dismissing attachment and outcome in diabetes: the mediating role of coping. J Soc Clin Psychol $2003 ; 22: 607-26$

26. Ciechanowski PS, Katon WJ, Russo JE, Walker EA. The patient-provider relationship: attachment theory and adherence to treatment in diabetes. Am J Psychiatry 2001;158:29-35.

27. Katon W, Von Korff M, Lin E, Simon G, Ludman E, Bush T, Walker E, Ciechanowski P, Rutter C. Improving primary care treatment of depression among patients with diabetes mellitus: the design of the pathways study. Gen Hosp Psychiatry 2003;25:158-68.

28. McCulloch D, Price M, Hindmarsh M, Wagner E. A population-based approach to diabetes management in a primary care setting: early results and lessons learned. Eff Clin Pract 1998;1:12-22.

29. Deleted in proof.

30. Scharfe E, Bartholomew K. Reliability and stability of adult attachment patterns. Pers Relat 1994;1:23-43.

31. Toobert DJ, Hampson SE, Glasgow RE. The summary of diabetes selfcare activities measure: results from 7 studies and a revised scale. Diabetes Care 2000;23:943-50.

32. Spitzer R, Kroenke K, Williams J. Validation and utility of a self-report version of PRIME-MD: the PHQ primary care study. Primary Care Evaluation of Mental Disorders: Patient Health Questionnaire. JAMA 1999;282:1737-44.

33. Kroenke K, Spitzer RL, Williams JBW. The PHQ-9: validity of a brief depression severity measure. J Gen Intern Med 2001;16:606-13.

34. Ludman EJ, Simon GE, Rutter CM, Bauer MS, Unützer J. A measure for assessing patient perception of provider support for self-management of bipolar disorder. Bipolar Disord 2002;4:249-53.

35. Bonomi AE, Wagner EH, Glasgow RE, VonKorff M. Assessment of chronic illness care (ACIC): a practical tool to measure quality improvement. Health Serv Res 2002;37:791-820.

36. Fishman P, Goodman M, Hornbrook M, Meenan RT, Bachman DJ, O'Keefe Rosetti MC. Risk adjustment using automated pharmacy data: the Rx Risk model. Med Care 2003;41:84-99.

37. Starfield B, Weiner J, Mumford L, Steinwachs D. Ambulatory care groups: a categorization of diagnoses for research and management. Health Serv Res 1991;26:53-74

38. Unützer J, Simon GE, Pabiniak C, Bond K, Katon W. The use of administrative data to assess quality of care for bipolar disorder in a large staff model HMO. Gen Hosp Psychiatry 2000;22:1-10.

39. Goldstein D, Little R, Lorenz R, Malone JI, Nathan DM, Peterson CM. Tests of glycemia in diabetes. Diabetes Care 1995;18:896-909.

40. Baron RM, Kenny DA. The moderator-mediator variable distinction in social psychological research: conceptual, strategic, and statistical considerations. J Pers Soc Psychol 1986;51:1173-82.

41. Shrout PE, Bolger N. Mediation in experimental and nonexperimental studies: new procedures and recommendations. Psychol Methods 2002; 7:422-45.
42. Kafetsios K, Nezlek, JB. Attachment styles in everyday social interaction. Eur J Soc Psychol 2002;32:719-35.

43. Dozier M. Attachment organization and treatment use for adults with serious psychopathological disorders. Dev Psychopathol 1990;2:47-60.

44. Main M, Kaplan N, Cassidy J. Security in infancy, childhood, and adulthood: a move to the level of representation. In: Bretherton I, Waters E, editors. Growing points of attachment theory and research. Monogr Soc Res Child Dev 1985:50(1-2, serial no. 209);66-104.

45. Covey SR. The seven habits of highly effective people: restoring the character ethic. New York: Simon and Schuster; 1990.

46. Joplin JR, Nelson DL, Quick JC. Attachment behavior and health: relationships at home and work. J Organiz Behav 1999;20:783-96.

47. Gregory RJ, Berry SL. Measuring counterdependency in patients with chronic pain. Psychosom Med 1999;61:341-5.

48. Carmody TP. Affect regulation, nicotine addiction, and smoking cessation. J Psychoactive Drugs 1989;21:331-42.

49. Ciechanowski PS, Walker AE, Katon WJ, Russo JE. Attachment theory: a model for health care utilization and somatization. Psychosom Med 2002;64:660-7.

50. Hunter JJ, Maunder RG: Using attachment theory to understand illness behavior. Gen Hosp Psychiatry 2001;23:177-82.

51. Ciechanowski PS, Katon WJ, Russo JE, Hirsch IB. The relationship of depressive symptoms to symptom reporting, self-care and glucose control in diabetes. Gen Hosp Psychiatry 2003;25:246-52.

52. Golden SH, Williams JE, Ford DE, Yeh HC, Paton Sanford C, Nieto FJ, Brancati FL. Depressive symptoms and the risk of type 2 diabetes: the Atherosclerosis Risk in Communities study. Diabetes Care 2004;27: 429-35.

53. Kirkpatrick LA, Hazan C. Attachment styles and close relationships: a four-year prospective study. Pers Relat 1994;1:123-42.

54. Hamilton CE. Continuity and discontinuity of attachment from infancy through adolescence. Child Dev 2000;71:690-4.

55. Waters E, Merrick SK, Treboux D, Crowell J, Albersheim L. Attachment security in infancy and early adulthood: a twenty-year longitudinal study. Child Dev 2000;71:684-9.

56. Klohnen EC, Oliver JP. Working models of attachment: a theory-based prototype approach. In: Simpson JA, Rholes WS, editors. Attachment theory and close relationships. New York: Guilford Press; 1998. p. $115-40$.

57. George C, Kaplan N, Main M. The Berkeley adult attachment interview. Unpublished protocol. University of California, Berkeley: 1985.

58. Stein H, Jacobs NJ, Ferguson KS, Allen JG, Fonagy P. What do adult attachment scales measure? Bull Menninger Clin 1998;62:33-82.

59. Maunder RG, Hunter JJ. Attachment and psychosomatic medicine: developmental contributions to stress and disease. Psychosom Med 2001; 63:556-67.

60. Rollnick S, Mason P, Butler C. Health behavior change: a guide for practitioners. Edinburgh, New York: Churchill Livingstone; 1999.

61. D'Zurilla TJ. Problem-solving therapy: a social competence approach to clinical intervention. D'Zurilla TJ, Nezu AM, editors. New York: Springer Pub; 1999

62. Thompson D, Ciechanowski PS. Attaching a new understanding to the patient-physician relationship in family practice. J Am Board Fam Pract 2003;16:219-26. 